\title{
Comparison of utilization of urgent care and primary care 2011-2015
}

\author{
Trudy Millard Krause ${ }^{1 *}$, Cecilia Ganduglia-Cazaban ${ }^{1}$, Linda B Piller ${ }^{2}$ and Vidya Venkataraman ${ }^{1}$ \\ ${ }^{1}$ Department of Management, Policy and Community Health, UTHealth School of Public Health, USA \\ ${ }^{2}$ Department of Epidemiology, Human Genetics \& Environmental Sciences, UTHealth School of Public Health, USA
}

\section{Introduction}

This study reviewed the patterns of utilization of urgent care services across recent years and compared those trends to that of primary care utilization. We wanted to explore whether urgent care centers are beginning to serve the population for primary care needs, primarily due to convenience issues related to days and times of availability. Additionally, we wanted to explore the relationship between urgent care services and pre or post primary-care treatment. Costs of services between the two settings was also compared.

The researchers reviewed national claims data for patients presenting to urgent care providers across five years: 2011-2015. Rates of utilization across geographic locations and age and gender groups are compared to rates of the use of primary care office-based services. This serves as a descriptive study to identify the utilization patterns, payment amounts, and billed diagnoses in urgent care settings. It also provides a descriptive review of the patient characteristics and the days of presentation for service. The study attempts to identify trends and shift in the source of treatment for minor acute injuries/complaints.

\section{Background}

The American Academy of Urgent Care Medicine (AAUCM) [1] defines urgent care service as "the provision of immediate medical service offering outpatient care for the treatment of acute and chronic illness and injury". Urgent care centers are delivery centers that provide ambulatory urgent care services, generally on an unscheduled basis, for injuries or illnesses that require immediate attention but are not severe enough to require hospital-based or free-standing emergency care by an emergency medicine specialist. Urgent care services are generally provided by family medicine specialists with support from physician extenders such as nurse practitioners and physician assistants.

According to the 2013 Benchmark Study from the Urgent Care Association of America (the most recent available report), urgent care centers see an average of 14,000 patient care visits in 2013, with an average of 4 patient care visits per hour and 40 visits per day. The centers report that only $63 \%$ of the urgent care patients report a relationship with an external primary care provider (PCP). And, 15\% of the urgent care centers reporting in 2013 provided ongoing primary care services as well as urgent care [2]. The Urgent Care Association of America reports that there are currently more than 6,400 urgent care centers in the United States ${ }^{3}$, while others report the number closer to $9,000[4,5]$. The number is increasing annually, at an annual growth rate of 300-600 clinics per year, with a recent surge since 2010 [3].

The proliferation in urgent care centers is commonly attributed to patient demand for shorter wait times, accessibility, and after hours availability [4]. The Urgent Care Association of American 2013 Benchmark Survey reported that $90 \%$ of the patients were seen by a provider within 30 minutes or less (69\% under 20 minutes) and $84 \%$ completed the visit in 60 minutes or less. Among survey respondents, $97 \%$ of the urgent care centers were open 7 days a week, and urgent care clinics offered services for an average of 4,100 hours per year [2].

Many patients visit Emergency Departments (ED) for nonemergent conditions that could be treated by private providers in clinics or urgent care centers. Many of these patients lack a primary care provider, may be uninsured, and tend to be very young, i.e., brought to the ED by parents, or are age over 65 . These visits may involve long waits, but nonetheless offer round-the-clock access to medical care. The overall cost of ED visits is high compared to other care providers [6]. Weinick, et al reviewed data from emergency department visits and concluded that between $13.7 \%$ and $27.1 \%$ of all emergency department visits could be serviced by an urgent care center or retail clinic, with a corresponding cost savings. Their conclusion was related to the acuity level of the presenting conditions, with most being minor illnesses, strains, and fractures [6]. They suggest that the incentive for non-emergent use of the emergency department is related to accessibility and convenience. A 2013 review of articles on the topic of non-urgent emergency department use concluded that younger age and convenience were factors that contributed to the choice of place of service [7].

In addition to offering convenience, urgent care centers provide an economic alternative to emergency departments, ranging between \$228 - \$414 less than a comparable hospital-based emergency department visit [8]. Urgent care centers tend to operate in areas of high population and higher income levels, with a concentration of people with employer-sponsored coverage and rapid growth. Suburban areas of large cities are common sites for urgent care centers, who target employed adults with young families.

\section{Primary Care}

As the presence of urgent care centers increases, the nation is confronting changes in the practice of primary care medicine. The American Academy of Family Practice defines primary care as medical services for persons with any undiagnosed sign, symptom, or health

${ }^{\star}$ Correspondence to: Trudy Millard Krause,Department of Management, Policy and Community Health, UTHealth School of Public Health, USA, 713-8058422; Fax: 713-500-9493; E-mail: Trudy.M.Krause@uth.tmc.edu

Received: March 29, 2018; Accepted: April 13, 2018; Published: April 16, 2018 
concern (the "undifferentiated" patient) not limited by problem origin (biological, behavioral, or social), organ system, or diagnosis [9]. Specifically, primary care is generally the first point of contact care for persons with any undiagnosed health concern. Primary care also provides ongoing patient management for organ- or problem- specific conditions, assuming the responsibility for referral to other health services and specialists. Primary care services are considered a critical component of the healthcare system.

The landscape of primary care practice has changed in recent years. While demand for primary care services has grown, the supply of primary care physicians is unable to keep up [10]. The Health Resources and Services Administration - HRSA projects primary care demand to increase $14 \%$ from 2010 to 2020 and primary care physician supply to increase only $8 \%$ over the same time [10]. HRSA concludes that changes to how primary care is delivered is inevitable. One effect of the shortage is the increase in patient panel size - the number of patients under the care of a single physician [11]. The concept of a patient panel goes to the core of primary care: that general individual patient health management is the responsibility of the PCP, requiring a relationship between patient and physician. Patient health management involves continuous, comprehensive and coordinated healthcare between the patient and the physician which develops a shared knowledge of health status and treatment plans [12].

Despite the principle role of the primary care physician, many insured and uninsured persons do not recognize a "usual source of care". In terms of access, it is reported that nearly one in five Americans lacks adequate access to primary care due to a shortage of primary care physicians [13-15]. In terms of utilization, a recent report using Medical Expenditure Panel Survey Data form 2012 found that approximately 53.4 million Americans aged 18-64 do not report having a usual source of care [16]. People aged between 18 - 34 were the most likely to report lacking usual source of care $(46.6 \%$ of men and $32.3 \%$ of women) followed by those 35-44 (38.25 of men and 23.5 percent of women). The uninsured were the group most likely to report lacking usual care $(65.8 \%$ of men and $49.2 \%$ of women), however those with insurance still reported high rates of lack of usual source of care (over $26 \%$ and $16.6 \%$ of men and women respectively) [16].

Even among those with an identified PCP only 57\% report having access to same or next-day appointments with that physician and $63 \%$ report difficulty getting access to care on nights, weekends or holidays without going to the emergency room. Twenty percent $(20 \%)$ of adults waited six (6) days or more to see a doctor when they were sick in 2010 [5].

Over the past decades factors both extrinsic and intrinsic to medical practice have influenced new practice choices for primary care physicians, stressing even more the availability of PCP care. The traditional self-employed individual or small group, fee-for-service, practice model, is undergoing transition to large group practices, often hospital-owned and managed, with salaried physicians and bundled or capitation payments as determined by the reimbursement body [17]. The vulnerability of Medicare reimbursements continues to threaten the traditional office visit-centric model which has been the core of primary care practice $[18,19]$. In addition, the aging of the US population and the increased number of insured, predominantly under the Affordable Care Act, will increase the need of the already inadequate number of primary care providers. Moreover, the overall population is characterized by multiple comorbidities.

\section{Access and Convenience}

There is evidence that lacking a usual source of care may drive people to seek care from other more "accessible" places such as an emergency department or urgent care center. However, some studies have found that having a physician identified as a usual source of care may not be enough to prevent emergency department utilization. Rust et al analyzed data from the National Health Interview Survey and found that individuals reporting barriers to timely access to care were more likely to visit the emergency department. The answers to the survey which were found to have a significant association with emergency department visits included (1) not being able to get in touch with doctor over the phone, (2) not being able to get an appointment soon enough or (3) office not open convenient hours. Long waiting times at doctor's office was also found to be significantly associated [20]. A study on Medicaid population had similar findings, and was able to report that these timely access barriers were more common among this population [21].

Weber and colleagues also concluded that the uninsured or those lacking usual source of care could not explain the increasing rate of ED utilization between 1996 and 2004 since the statistical test for trend was not significant for these two groups. However, they identified that the increase in ED service utilization could be tracked to an increase in number of visits by those with a physician's office identified as a usual source of care and individuals above $400 \%$ of the poverty line [22]. These findings supported the results previously reported by Ragin and colleagues who after surveying and analyzing clinical records of several thousand ED users found that use of ED services was for most people a choice often driven by convenience, a lack of access or dissatisfaction with their other sources of care [23].

Many primary care services are for unscheduled, acute complaints. Yet, it has been shown that there is a decrease in availability of PCPs along with an increase in persons without a regular source of treatment, and a perception of the inconvenience of standard office hours and wait times. The appeal of urgent care centers focuses on convenience and access. The urgent care centers are open extended hours and days, and due to the walk-in strategy, no appointments are required. Wait time is generally minimal. For these reasons urgent care becomes an attractive alternative to delayed regular-hours appointments with primary care physicians when illness or injury strikes un-expectantly.

\section{Methodology}

The retrospective study reviewed claims data from the Truven Health MarketScan ${ }^{\odot}$ Research Databases from 2011-2015. The MarketScan ${ }^{\odot}$ Research Databases are constructed from commercially insured, paid medical and prescription drug claims. Collectively, the databases incorporate data from almost 350 commercial payers providing coverage for nearly $80 \%$ of commercially insured individuals in the United States.

The data were filtered to identify urgent care visits in the outpatient claims files by the use of the place of service code (STDPLC code 20). Because urgent care visits are outpatient, with a duration of under 24 hours, and include all services on one bill, a single claim was deemed to represent one visit. Urgent care visits that resulted in an inpatient admission to the same provider, as indicated on the same claim, were excluded. Primary care visits were identified by the use of the place of service code that indicates office, (STDPLC code 11) and provider specialty codes for Internal Medicine, Family Practice, and Geriatrician. Although Obstetric/Gynecologists are often included as primary care, they were excluded in this comparison. 
Utilization and price data were compared between urgent care visits and primary care visits to assess variation and trends across regions and across years. Regions were defined as follows: Northeast (9 states), North Central (12 states), South (17 states) and West (13 states). Usual source of care was assessed per urgent care patient to identify the ability to access a primary care physician instead of using an urgent care center. If an individual had evidence of at least one primary care visit in the preceding 12 months, it was determined that he/she had access to a PCP and thus had a usual source of care. Additionally, follow up visits (same day, within one week and one month) post urgent care services were assessed to determine if the urgent care patient was treated by a primary care provider after the urgent care visit. Statistical significance was measured using the two-proportion chi-square and risk difference yield.

\section{Results}

The data yielded a total of $15,138,654$ visits to urgent care centers across 2011-2015. The year with the greatest number of UC visits reported a total of 4,097. Primary care claims reflected a total of $294,376,160$ visits across the same time period, with $69,079,869$ as the largest single year count. The total count of members seeking urgent care services at least once in a year was $10,287,837$, an average of 2,057,567 per year. Primary care visits occurred for 93,338,214 members over four years, an average of $18,667,643$ per year. The count of total members in the data set fluctuated across years (due to fluctuation in data contribution to Truven MarketScan ${ }^{\circledR}$ ), thus rates of visits per 1000 member years was used as a better reflection of trend across years.

Table 1 shows the rates of visits in relation to the overall population, comparing urgent care to primary care across 5 years and by region. Primary care visits per 1000 members per year greatly exceed the rate of urgent care visits. Yet, the increase in utilization of urgent care services is evident in Figure 1, which illustrates the continuous annual increase across years (up 44\% in 2012,36\% in 2013, 18\% in 2014, and $16 \%$ in 2015), whereas the rate of primary care utilization increased only slightly ( $0 \%$ in $2012,7 \%$ in $2013,0 \%$ in 2014 , and $1 \%$ in 2015 ). Despite the lower trend in rate per 1000 for primary care, when viewed as a mean count of visits per patient (patient who used primary care services) primary care visits did not decrease over the years. The same is true for the mean count of urgent care visits per urgent care patient. In fact, the average number of visits per patient (users of primary care services) remained relatively consistent at 3.21 visits per patient. The average number of visits per patient for urgent care (users of urgent care) also remained steady at 1.47 .
An obvious difference between the utilization of the two services is made clear when reviewing the day of week for which services were provided. Table 2 provides the percentage by day of the week for each year, comparing visits to urgent care (UC) and primary care (PC). For primary care, $96 \%$ of visits occur during weekdays, whereas for urgent care, the percentage of visits are more evenly spread across all days of the week, with $28 \%-29 \%$ occurring on weekend days. It was not possible, in this data source, to evaluate the times of visits. However, use of urgent care centers on weekend days is an indication of convenience and access demand for unscheduled visits. The percent of visits in each setting was also reviewed and it was found that overall, primary care visits remained consistent across each of the 12 months of the year, but some seasonality was shown for urgent care. The months of November, December and January accounted for a higher percentage of visits than other months in the urgent care setting (being 12\%-43\% more active than other months).

We additionally assessed the pattern of utilization of urgent care services to suggest convenience or access. We looked at the percentage of urgent care utilizers who had evidence of a "usual source of care" by searching for a documented primary care visit in the 12 months prior to the urgent care visit. The percentage averaged $45 \%$, and ranged from $43 \%$ in 2013/2012 (persons with urgent care visit in 2013 who had a primary care source in 12 months prior -2012-2013) to $47 \%$ in $2015 / 2014$. This finding indicates that many urgent care utilizers had a "usual source of care" but chose not to present to the primary care provider. Table 3 reports the percentage of urgent care patients with primary care visits both prior and post the urgent care visit in both a one-week and a one-month time span. We found that over five years, only $5 \%$ of urgent care visits were followed by a primary care visit within one week, and $7 \%$ were followed up with a primary care visit within 30 days, suggesting that the urgent care visit was regarded as sufficient treatment.

In order to assess reasons for visits, we evaluated the primary diagnoses on each urgent care claim and each primary care claim. The five top billed diagnoses for urgent care visits were not related to injury or emergency complaints,but were instead conditions of acute distress such as acute sinusitis, acute pharyngitis, acute bronchitis, acute upper respiratory infections, and urinary tract infection. Within the remaining top ten reasons, urgent care reported streptococcal sore throat, cough, fever, otitis media and sprain of ankle. The top five billed diagnoses for primary care included general patient management such as routine general medical exam, hypertension, diabetes, and vaccinations. Within the top 10 reasons for a primary care visit, similar acute diagnoses as seen in urgent care were noted such as: acute pharyngitis, acute upper respiratory infection, and acute

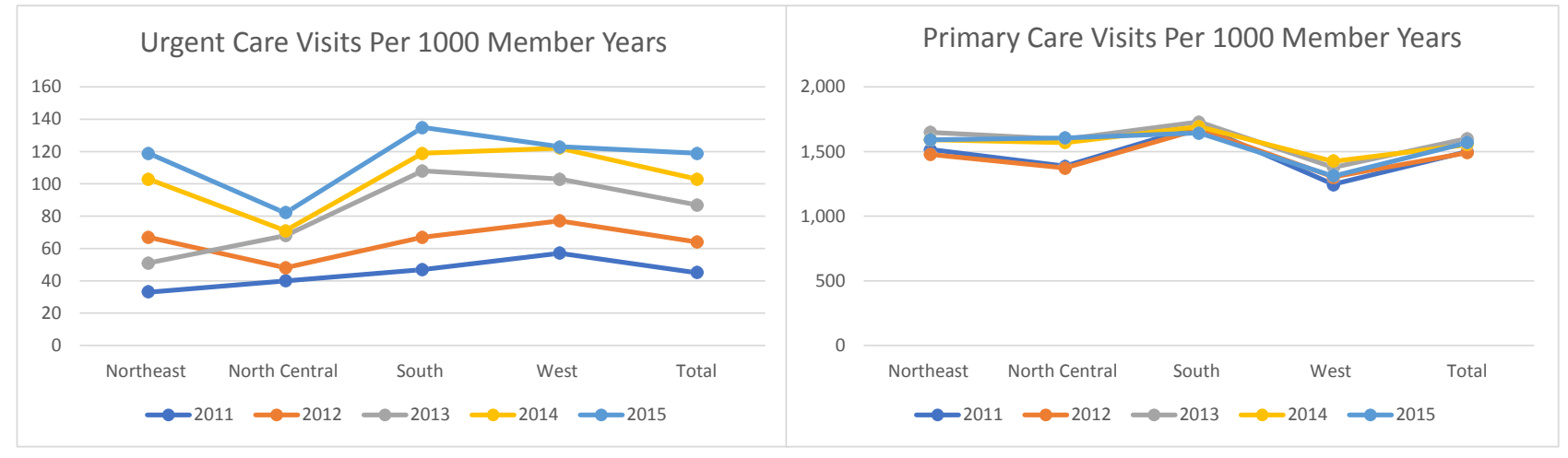

Figure 1. Rate trends of urgent care and primary care visits across years and region. 
Table 1. Visits per 1000 Member Years.

\begin{tabular}{|c|c|c|c|c|c|c|c|c|c|c|c|}
\hline \multicolumn{6}{|c|}{ VISITS PER 1000 Member Years: URGENT CARE } & \multicolumn{6}{|c|}{ VISITS PER 1000 Member Years: PRIMARY CARE } \\
\hline & North-east & $\begin{array}{c}\text { North } \\
\text { Central }\end{array}$ & South & West & Total & & North-east & $\begin{array}{l}\text { North } \\
\text { Central }\end{array}$ & South & West & Total \\
\hline 2011 & 33 & 40 & 47 & 57 & 45 & 2011 & 1,515 & 1,388 & 1,699 & 1,246 & 1,500 \\
\hline 2012 & 67 & 48 & 67 & 77 & 64 & 2012 & 1,476 & 1,373 & 1,673 & 1,303 & 1,491 \\
\hline 2013 & 51 & 68 & 108 & 103 & 87 & 2013 & 1,648 & 1,595 & 1,730 & 1,377 & 1,601 \\
\hline 2014 & 103 & 71 & 119 & 122 & 103 & 2014 & 1,591 & 1,568 & 1,693 & 1,424 & 1,553 \\
\hline 2015 & 119 & 82 & 135 & 123 & 119 & 2015 & 1,591 & 1,605 & 1,644 & 1,310 & 1,568 \\
\hline
\end{tabular}

Table 2. Percentage of urgent care (UC) and primary care (PC) visits by day of the week.

\begin{tabular}{|c|c|c|c|c|c|c|c|c|c|c|}
\hline & \multicolumn{2}{|c|}{2011} & \multicolumn{2}{|c|}{2011} & \multicolumn{2}{|c|}{2013} & \multicolumn{2}{|c|}{2014} & \multicolumn{2}{|c|}{2015} \\
\hline & UC & PC & UC & PC & UC & PC & UC & PC & UC & PC \\
\hline Monday & 16.04 & 20.89 & 16.38 & 21.10 & 16.20 & 21.37 & 16.20 & 21.45 & 16.30 & 21.16 \\
\hline Tuesday & 14.05 & 20.53 & 13.67 & 20.11 & 14.34 & 20.06 & 14.19 & 20.52 & 14.33 & 20.46 \\
\hline Wednesday & 13.83 & 18.66 & 13.79 & 18.42 & 13.64 & 18.45 & 13.97 & 18.43 & 14.08 & 19.01 \\
\hline Thursday & 13.17 & 18.84 & 13.26 & 18.91 & 13.23 & 18.44 & 12.97 & 18.45 & 13.49 & 18.46 \\
\hline Friday & 13.90 & 17.39 & 13.88 & 17.58 & 13.89 & 17.49 & 13.79 & 17.15 & 13.70 & 16.87 \\
\hline Saturday & 14.95 & 2.78 & 14.62 & 2.86 & 14.60 & 2.94 & 14.54 & 2.91 & 14.07 & 2.80 \\
\hline Sunday & 14.06 & 0.90 & 14.40 & 1.02 & 14.11 & 1.24 & 14.34 & 1.09 & 14.03 & 1.24 \\
\hline Weekday & 70.99 & 96.31 & 70.98 & 96.12 & 71.30 & 95.82 & 71.12 & 96.00 & 71.90 & 95.96 \\
\hline Weekend & 29.01 & 3.69 & 29.02 & 3.88 & 28.71 & 4.18 & 28.88 & 4.00 & 28.10 & 4.04 \\
\hline
\end{tabular}

Two proportion chi-square and risk difference yield significance for all at $<0.001$

Table 3. Consecutive Urgent Care (UC) and Primary Care (PC) Visits

\begin{tabular}{|c|c|c|c|c|c|c|c|}
\hline \multicolumn{8}{|c|}{ UC patients with a PC visits within 1 week of each other } \\
\hline & $\begin{array}{c}\text { Total Members with } \\
\text { UC Visit }\end{array}$ & \multicolumn{2}{|c|}{ PC visit 1 week before $U C$ visit } & \multicolumn{2}{|c|}{ PC visit 1 week after $\mathrm{UC}$ visit } & \multicolumn{2}{|c|}{ PC-UC visit same day } \\
\hline & & (n) & $(\%)$ & (n) & $(\%)$ & (n) & (\%) \\
\hline 2011 & $1,410,633$ & 41,017 & 2.91 & 80,031 & 5.67 & 17,169 & 1.22 \\
\hline 2012 & $2,023,261$ & 40,674 & 2.01 & 97,388 & 4.81 & 23,762 & 1.17 \\
\hline 2013 & $2,117,921$ & 45,111 & 2.13 & 93,000 & 4.39 & 23,307 & 1.10 \\
\hline 2014 & $2,789,692$ & 55,765 & 2.00 & 117,702 & 4.22 & 30,747 & 1.10 \\
\hline 2015 & $1,946,330$ & 46,224 & 2.37 & 103,338 & 5.31 & 23,350 & 1.20 \\
\hline \multicolumn{8}{|c|}{ UC patients with a PC visits within 1 month of each other } \\
\hline & $\begin{array}{c}\text { Total Members with } \\
\text { UC Visit }\end{array}$ & \multicolumn{2}{|c|}{ PC visit 1 month before $U C$ visit } & \multicolumn{2}{|c|}{$P C$ visit 1 month after $\mathrm{UC}$ visit } & & \\
\hline & & (n) & $(\%)$ & (n) & $(\%)$ & & \\
\hline 2011 & $1,410,633$ & 112,339 & 7.96 & 100,541 & 7.13 & & \\
\hline 2012 & $2,023,261$ & 144,004 & 7.12 & 143,000 & 7.07 & & \\
\hline 2013 & $2,117,921$ & 153,851 & 7.26 & 146,153 & 6.90 & & \\
\hline 2014 & $2,789,692$ & 196,048 & 7.03 & 158,176 & 5.67 & & \\
\hline 2015 & $1,946,330$ & 143,120 & 7.35 & 140,334 & 7.21 & & \\
\hline
\end{tabular}

sinusitis. This finding confirmed that most urgent care visits were for acute conditions that might be treated in primary care settings. This again suggests that urgent care is a convenience and potentially used as a substitute for primary care for select acute conditions, possibly due to time, access, and lack of usual source of care.

We next explored if there were any price differences between urgent care and primary care. To derive the median payment amounts by year, we excluded claims that included an inpatient admission (generally from a hospital-based urgent care center) which grossly inflated the total cost of the claim. Payment is defined as allowed amount which is the net paid amount inclusive of out-of-pocket payment. We also excluded claims that had a 0 or negative allowed. The median payment for an urgent care visit was consistently higher than that of primary care (average 1.36 times) across years and across regions ( $p$ value $<0.001$ ). Table 4 compares the median allowed amounts for urgent care visits (average \$126.98) and primary care visits (average \$94.20).
The trend across years was less for urgent care, which increased $14 \%$ from 2011 to 2015, than for primary care, which increased 15\% from 2011 to 2015. To insure consistency in services, we compared the two provider types and concluded that similar procedures were conducted for similar complaints based on billed procedural codes, and laboratory charges were included in both claim sets. This finding suggests that urgent care visits are much more costly than primary care visits, despite serving similar complaints and including similar services.

Finally, because provider commercial payments vary based on contracting, we reviewed the variance in median allowed amounts by provider participation in-network or out-of-network. The data had some claims with network status marked unknown and they are not reported in Table 5. It was interesting to note that in some regions and some years, the in-network median allowed amount was greater than the out-of-network median amount. Overall, primary care median allowed amounts for in-network providers were between $74 \%$ - $76 \%$ of urgent care median allowed amounts [24-39]. 
Table 4. Median allowed amount per claim (visit). Note: highlighted cells indicate in-network median is greater than out-of-network

\begin{tabular}{|c|c|c|c|c|c|c|c|c|c|c|c|}
\hline \multicolumn{6}{|c|}{ MEDIAN ALLOWED AMOUNT: URGENT CARE } & \multicolumn{6}{|c|}{ MEDIAN ALLOWED AMOUNT: PRIMARY CARE } \\
\hline & North-east & $\begin{array}{l}\text { North } \\
\text { Central }\end{array}$ & South & West & Total & & North-east & $\begin{array}{l}\text { North } \\
\text { Central }\end{array}$ & South & West & Total \\
\hline 2011 & 138 & 100 & 127 & 110 & 118 & 2011 & 79 & 83 & 88 & 97 & 86 \\
\hline 2012 & 155 & 102 & 129 & 110 & 125 & 2012 & 82 & 89 & 92 & 98 & 91 \\
\hline 2013 & 160 & 108 & 132 & 114 & 128 & 2013 & 87 & 90 & 92 & 100 & 92 \\
\hline 2014 & 162 & 108 & 132 & 117 & 130 & 2014 & 92 & 96 & 97 & 102 & 97 \\
\hline 2015 & 150 & 112 & 132 & 130 & 134 & 2015 & 89 & 100 & 98 & 118 & 99 \\
\hline \multicolumn{6}{|c|}{$\begin{array}{l}\text { MEDIAN ALLOWED AMOUNT: URGENT CARE } \\
\text { In Network }\end{array}$} & \multicolumn{6}{|c|}{$\begin{array}{l}\text { MEDIAN ALLOWED AMOUNT: PRIMARY CARE } \\
\text { In Network }\end{array}$} \\
\hline & North-east & $\begin{array}{l}\text { North } \\
\text { Central }\end{array}$ & South & West & Total & & North-east & $\begin{array}{l}\text { North } \\
\text { Central }\end{array}$ & South & West & Total \\
\hline 2011 & 117 & 99 & 126 & 115 & 115 & 2011 & 76 & 83 & 88 & 101 & 86 \\
\hline 2012 & 125 & 102 & 128 & 110 & 119 & 2012 & 80 & 89 & 92 & 98 & 91 \\
\hline 2013 & 134 & 106 & 130 & 114 & 124 & 2013 & 83 & 91 & 93 & 101 & 95 \\
\hline 2014 & 165 & 108 & 131 & 116 & 130 & 2014 & 91 & 96 & 97 & 102 & 97 \\
\hline 2015 & 151 & 111 & 132 & 130 & 134 & 2015 & 88 & 100 & 98 & 117 & 99 \\
\hline \multicolumn{6}{|c|}{$\begin{array}{c}\text { MEDIAN ALLOWED AMOUNT: URGENT CARE } \\
\text { Out of Network }\end{array}$} & \multicolumn{6}{|c|}{$\begin{array}{l}\text { MEDIAN ALLOWED AMOUNT: PRIMARY CARE } \\
\text { Out of Network }\end{array}$} \\
\hline & North-east & $\begin{array}{l}\text { North } \\
\text { Central }\end{array}$ & South & West & Total & & North-east & $\begin{array}{l}\text { North } \\
\text { Central }\end{array}$ & South & West & Total \\
\hline 2011 & 145 & 98 & 130 & 99 & 102 & 2011 & 100 & 92 & 97 & 86 & 91 \\
\hline 2012 & 135 & 85 & 140 & 140 & 126 & 2012 & 106 & 83 & 100 & 117 & 102 \\
\hline 2013 & 144 & 89 & 142 & 144 & 133 & 2013 & 108 & 87 & 101 & 121 & 105 \\
\hline 2014 & 142 & 110 & 135 & 147 & 140 & 2014 & 108 & 84 & 105 & 125 & 106 \\
\hline 2015 & 145 & 121 & 140 & 155 & 145 & 2015 & 106 & 95 & 103 & 144 & 106 \\
\hline
\end{tabular}

\section{Limitations}

This study was limited to commercial claims data, thus use of urgent care services for other populations such as Medicaid and Medicare are not considered, and results may differ for those consumers. Additionally, claims data are limited to services reported for reimbursement purposes and clinical factors not recorded cannot be considered. Furthermore, it is assumed from previous reports that urgent care centers are most often located in metropolitan areas, whereas primary care services are offered in all localities. This geographic difference may contribute to the variations in reported rates. Finally, the method for identifying usual source of care (claims history) may not accurately reflect patient-provider relationships.

\section{Conclusions}

Urgent care services are increasing each year. Yet, the increase in the rate of urgent care utilization does not impact the rate of primary care visits. The convenient days of operation for urgent care providers provides a convenience factor for persons seeking treatment of acute conditions which may be effectively treated in a primary care setting. Many of the patients reporting to an urgent care center have no "usual source of care", which may further prompt their use of urgent care.

Despite serving similar patient populations, and treating similar acute complaints, urgent care visits are much more costly than primary care. Some have suggested that urgent care services assist primary care providers in deflecting the patients with unscheduled appointments, with the hope that they will return to the primary care provider for follow up. The follow up visits to a primary care provider occur only in $7.95 \%$ of visits when allowing for 30 days. Therefore, it might be concluded that urgent care is meeting a need for convenience, and potentially replacing primary care for certain acute complaints. The minimal degree of follow up could be reflective of patient failure to comply with a referral or lack of referral from the urgent care provider to coordinate with primary care follow up.

\section{References}

1. AAUCM (2015) American Academy of Urgent Care Medicine.

2. Urgent Care Association of America (2013) Urgent Care Benchmarking Survey Results.

3. Urgent Care Association of America (2015) Providing leadership, education resources for the successful practise of urgent care.

4. Yee T, Lechner A, Boukus E (2013) The Surge in Urgent Care Centers; Emergency Department Alternative or Costly Convenience? Res Brief 26: 1-6.

5. Future of Urgent Care (2015) American Academy of Urgent Care Medicine.

6. Weinick R, Burns R, Mehrotra A (2010) Many emergency department visits could be managed at urgent care centers and retail clinics. Health Affairs 29: 9.

7. Uscher-Pines L, Pines J, Kellermann A, Gillen E, Mehrotra A (2013) Deciding to Visit the Emergency Departent for Non-Urgent Conditions: A Systematic Review of the Literature. Am J Manag Care 19: 47-59.

8. HCPro (2012) The Healthcare Executive's Guide to Urgent Care Centers and Freestanding EDs. Health Leaders Media pp. 1630-1636.

9. http://www.aafp.org/about/policies/all/primary-care.html

10. U.S. Department of Health and Human Services (2013) Health Resources and Services Administration, National Center for Health Workforce Analysis. Projecting the Supply and Demand for Primary Care Practitioners Through 2020. Rockville, Maryland: U.S.

11. Margolius D, Bodenheimer T (2010) Transforming primary care: from past practice to the practice of the future. Health Aff (Millwood) 29: 779-784. [Crossref]

12. Higgins A, Barnett J, Meads C, Singh J, Longworth L (2014) Does Convenience matter in healthcare delivery? A systematic review of convenience-based aspects of process utility. Value Health 8: 877-887.

13. AAFP (2015) Continuity of care, definition of, American Academy of Family Physicians.

14. Cullen KA, Mace KE, Arguin PM; Centers for Disease Control and Prevention (CDC) (2016) Malaria Surveillance - United States, 2013. MMWR Surveill Summ 65: 1-22. [Crossref]

15. National Association of Community Health Centers (2009) Primary Care Access: An Essential Building Block of Health Reform.

16. Davis K (2014) Statistical Brief \#461. Access to Health Care of Adult Men and Women, Ages 18-64, 2012. 
17. Victor R, Fuchs, Mark R Cullen (2015) The Transformation of US Physicians. JAMA 18: 1821-1822.

18. Donald A Barr (2012) Bending the Medicare Cost Curve for Physicians' Services: Lessons Learned from Canada. J Gen Intern Med 11: 1555-1559.

19. Linda Brookes (2014) Primary Care Trends to Watch in 2015. Medscape.

20. Rust G, Ye J, Baltrus P, Daniels E, Adesunloye B, et al. (2008) Practical barriers to timely primary care access: impact on adult use of emergency department services. Arch Intern Med 168: 1705-1710.

21. Cheung PT, Wiler JL, Lowe RA, Ginde AA (2012) National study of barriers to timely primary care and emergency department utilization among Medicaid beneficiaries. Ann Emerg Med 60: 4-10.

22. Weber EJ, Showstack JA, Hunt KA, Colby DC, Grimes B, et al. (2008) Are the uninsured responsible for the increase in emergency department visits in the United States? Ann Emerg Med 52: 108-115.

23. Ragin DF, Hwang U, Cydulka RK, Holson D, Haley LL Jr, et al. (2005) Emergency Medicine Patients' Access To Healthcare (EMPATH) Study Investigators, Reasons for using the emergency department: results of the EMPATH Study. Acad Emerg Med 12: 1158-1166.

24. Zamosky Lisa (2014) What retail clinic growth can teach physicians about patient demand. Medical Economics

25. Weinick RM, Bristol SJ, DesRoches CM (2009) Urgent care centers in the U.S.: findings from a national survey. BMC Health Serv Res 9: 79. [Crossref]

26. Scott DR, Batal HA, Majeres S, Adams JC, Dale R, et al. (2009) Access and care issues in urban urgent care clinic patients. BMC Health Services Research 9: 222.

27. Chang, JE, Brundage SC, Chokshi DA Convenient ambulatory care - promise, pitfalls, and policy. Health Policy Report, $N$ Engl J Med 373: 4.
28. Patwardhan A, Davis J, Murphy P, Ryan SF (2012) After hours access of conveni9ent care clinics and cost savings associated with avoidance of higher cost sites of care. Journal of Primary Care and Community Health 3: 243-245.

29. Fuchs VR, Cullen MR (2015) The transformation of US physicians. JAMA 313: 1821 1822. [Crossref]

30. Donald A Barr (2012) Bending the Medicare Cost Curve for Physicians' Services: Lessons Learned from Canada. Journal of General Internal Medicine 11: 1555-1559.

31. Linda Brookes (2014) Primary Care Trends to Watch in 2015. Medscape.

32. Villasenor S, Krouse HJ (2016) Can the use of urgent care clinics improve access to care without undermining continuity in primary care? J Am Assoc Nurse Pract 28: 335-341.

33. Tarja Heponiemi, Justin Presseau, Marko Elovainio (2015) On -call work and physicians' turnover intention: the moderating effect of job strain. Psychology, Health $\&$ Medicine.

34. Health Policy Brief (2012) Nurse Practitioners and Primary Care. Health Affairs.

35. Thomas Bodenheimer, Hoangmai H (2010) Pham. Primary Care: Current Problems and Proposed Solutions. Health Affairs 5: 799-805.

36. Elbert S Huang, Kenneth Finegold (2013) Seven Million Americans Live in Areas Where Demand for Primary Care May Exceed Supply by More than 10 Percent. Health Affairs 3: 614-621.

37. Robert F, St Peter, Marie C Reed, MHS, Peter Kempere (1999) Changes in the Scope of Care Provided by Primary Care Physicians. N Engl J Med 341: 1980-1985.

38. Bodenheimer T, Pham HH (2010) Primary care: current problems and proposed solutions. Health Aff (Millwood) 29: 799-805. [Crossref]

39. Elbert S Huang, Kenneth Finegold (2013) Seven Million Americans Live in Areas Where Demand for Primary Care May Exceed Supply by More than 10 Percent. Health Affairs 32: 614-621.

Copyright: ( 2018 Krause TM. This is an open-access article distributed under the terms of the Creative Commons Attribution License, which permits unrestricted use, distribution, and reproduction in any medium, provided the original author and source are credited. 